\title{
Commuting inequality, role of urban structure, and identification of disadvantaged groups in the Mexico City metropolitan area
}

\author{
Dorian Antonio Bautista-Hernández \\ University of Washington \\ dobautistah@gmail.com
}

\begin{abstract}
Cities in developing countries are undergoing a vigorous urbanization process marked by deep social and economic inequalities, which are reflected in transportation. This study analyzes one-way Average Commute Time (ACT) in the Mexico City Metropolitan Area, specifically regarding its spatial pattern in relation to the urban center and the differences between cars and public transportation. It also explores the urban structure drivers as well as the social dimension. Results show that ACT is lower for car drivers than for transit users. The curve depicting the relationship between ACT and distance to the center differs between private car and public transit, being semi-flat for the former and an inverted U-shaped curve for the latter. There is a higher spatial correlation for transit ACT than for car ACT. Based on the results from Ordinary Least Squares (OLS) and spatial regression models, travel times from TRANUS transport model show that job accessibility plays a significantly inverse role in determining ACT for transit users and car users alike. However, this response is not consistent according to observed travel times from the 2017 Household Origin Destination Survey (HODS17). In regard to population groups, migrants and indigenous populations display significantly longer commute times, especially when using public transit, providing evidence that these groups are disadvantaged.
\end{abstract}

\section{Introduction}

The study of the relationship between urban structure and commuting has produced a large body of research in the last few decades, primarily driven by concerns for the growth of negative social and environmental externalities involved in urban transportation. In the second half of the last century, an academic debate began in the US over how land use affects travel behavior, including commute distances and times, and the extent to which minority groups have a locational disadvantage condition to access jobs. Costs of traveling are not homogeneously dispersed in

\section{Article history:}

Received: May 15, 2019

Received in revised form:

February 14, 2020

Accepted: March 30, 2020

Available online: June 29, 2020

Copyright 2020 Dorian Antonio Bautista-Hernández

http://dx.doi.org/10.5198/jtlu.2020.1611

ISSN: 1938-7849 | Licensed under the Creative Commons Attribution - Noncommercial License 4.0

The Journal of Transport and Land Use is the official journal of the World Society for Transport and Land Use (WSTLUR) and is published and sponsored by the University of Minnesota Center for Transportation Studies. 
the city with disproportionate impact among localities and different population groups. For this reason, the concept of equity emerged as a key issue in urban transportation policy.

The debate about the relationship between built environment and travel behavior contrasts two main points of view. For some, land-use patterns play a fundamental role in determining travel behavior, and therefore associated initiatives should be applied to reduce congestion, air pollution and dependence on automobiles (Cervero, 1989; Cervero, 1996). On the other hand, some researchers dismiss the relevance of physical planning in favor of market-driven policies (Giuliano, 1991). In this context, a consensus on the way urban structure influences commuting has been elusive. Guerra (2013) argues that the detection of the influence of land use on travel behavior has been difficult in US cities because of factors such as car-oriented urban form, high car use rates, low population densities and co-localization processes. If this is true, it is reasonable to expect that in cities in developing countries, built environment exerts a stronger influence on travel behavior than in most US cities given the presence of more densely constructed environments and fewer car drivers. In this sense, some aspects of travel behavior have been tested. However, in order to define the relationship between commute time and urban structure, the evidence is still limited for cities in developing countries.

Regarding the social aspect of commuting, in the US the hypothesis stated by Kain (1968) triggered an important academic debate. Accoding to Kain, house market segregation and employment decentralization greatly increase the difficulty for low-income minorities to access jobs, especially for African Americans who live in the central city. In the case of social aspects of commuting in Latin America, there has been special interest in focusing mostly on evaluation of the area-level accessibility to certain opportunities. Although this has brought about insights concerning transportation problems of the urban poor in the Global South, urban structure determinants of such disadvantage remain to be analyzed. Specifically, the study of determinants of an observed mobility indicator such as travel time has been limited in the region. Moreover, the identification of population groups in disadvantage is often limited to low-income groups and/or people living in the periphery, but the identification of other groups has not been explored with the same intensity. This is vital in order to establish a more inclusive policy.

The study of transportation problems of disadvantage groups in the Global South is important because, in today's increasingly urbanized world, developing countries are absorbing most of this urban growth. Here, suburban expansion is dominated by poor and densely populated neighborhoods. According to Guerra (2017), many suburban residents of cities as diverse as Mumbai, Dakar and Bogotá have to deal with long and costly trips on multiple modes of public transportation to reach jobs centrally located. Benevenuto and Caulfield (2019) argue that, in the Global South, low research production has failed to inform transport policy in its role to alleviate poverty. In this sense, increasing efforts in research are needed to develop a more robust evidence about the interlinked association between urban form, mobilities and social deprived conditions.

In regard to the developing world, we still need to understand how commute time varies at neighborhood level beyond the dichotomy inner city/suburbs, as well as to analyze the relation between commute times and urban structure. Without knowledge of spatial patterns from commuting at neighborhood level, researchers are less capable to contribute to the design and implementation of accessibility improvement programs, which are often based on location (Shen, 2000). We need more research in order to understand the explanatory factors of one-way travel time to work in the Latin American context. This research needs to include its urban structure determinants as well as the social dimension evaluation which will allow us to identify the most disadvantaged groups. In US cities, where travel times are significantly lower for those commuting by car than for those who commute by transit, and where travel time is the most important factor for job access, it has been demonstrated that accessibility and one-way 
commute times are inversely associated (Shen, 2000). This association is considerably greater for public transit users than for those using a car for commuting (Kawabata $\&$ Shen, 2007). How does this relation behave in a Latin American city, where location is more important than differences in travel time between car and transit to increase job access? What aspects of urban structure are most determinant to commute times? These findings will be relevant to the overall Global South context.

This research aims to address two primary questions. The first is whether there are differences in the Average Commute Time (ACT) pattern with respect to the urban center between car and public transportation use. Additionally, it will evaluate the extent to which the periphery and the inner city are heterogeneous in commuting experiences. To this end, I calculated and visualized commute times for car and transit users separately, comparing data from two different sources. Furthermore, these values were graphed according to distance to the urban center. The second question was whether the association between employment accessibility and commute time is negative and if this is higher for public transit users than for people driving alone. The question was addressed using the ordinary least squares (OLS) regression and two typical spatial regression models that take into account spatial autocorrelation, the spatial lag model (Lag-ML) and the spatial error model (Err-ML). The models were estimated separately for average commute times (ACT) by driving alone and by public transit. In order to address the social aspects of commuting, the specification of regression models included different social groups that could be in travel disadvantage.

This study offers an exploration of the complex urban structure in developing world cities as a determinant of commute times and develops an interpretation to understand this relationship in the specific case study. Additionally, this paper demonstrates that other important population groups are potentially in disadvantage with respect to commute times cost besides the common focus on income.

This paper is organized in the following manner: in Section 2, the main approaches and findings in the study of urban structures and commute times in the US and its social dimensions, along with a specific description of these issues for the Mexico City Metropolitan Area (MCMA) and the state of the art for Latin America, are presented; in Section 3, the data and methods applied are described; in Section 4, the results of the descriptive and statistical analyses are presented; and in Section 5, I present my conclusions, summarize the main results of my research and discuss its implications for public transportation policy.

\section{$2 \quad$ Urban structure and social aspects of commuting}

\subsection{Urban spatial structure and commute time}

In journey-to-work literature, there are three broad sub-research areas that investigate the relationship between jobs and workers' housing locations and journeys-to-work. The first two inquire how proximity between housing and job locations affects both journey-to-work times and distances. In the first area, the effect of job/housing balance and commuting was studied. Initial advocates of this measure to decrease the need for commuting include Cervero $(1989,1996)$, though Giuliano (1991) is among his main critics. The study in the second sub-research area compared a theoretical minimum commute against an observed commute, given an actual distribution of jobs and housing. The difference was considered to be an excess of commute time and effort required (Giuliano \& Small, 1993). In the third sub-research area, the debate was about how, in metropolitan cities in the US, regional densities of employment and population have historically affected average commute times because of jobs and people decentralization in an emergent polycentric structure. Some researchers argue that commute times at the 
end of last century were shrinking (Gordon, Richardson, \& Jun, 1991), while others say it had increased at a modest pace (Rosseti \& Eversole, 1993).

An important urban process in the journey-to-work literature is the co-location of jobs and people and the role of land use in encouraging this co-location. Some authors consider the spatial transformation of cities from monocentric to polycentric structures as an adjustment process that mitigates some of the negative externalities that accompany urban growth, such as traffic congestion, and suggest that many individual households and firms "co-locate" in order to reduce commute times (Gordon \& Bumsoon, 2015) as an alternative for these problems, thus avoiding government planning intervention in land use. Other authors argue that there are barriers that limit the co-location process influence (Cervero \& Landis, 1992).

\subsection{Travel disadvantaged populations and commute times}

Travel disadvantage of certain groups has attracted attention in the social dimension of commuting. The first and most cited author in the US is Kain (1968), who developed the "Spatial Mismatch Hypothesis", which states that employment distribution for African Americans, who mainly live in the central city areas, is affected by segregation in the housing market, which thereby reduces job opportunities accessible to them. Furthermore, employment suburbanization aggravates the problem. Literature has debated this hypothesis. Shen (2000) argues than one of the reasons for which the literature brings contested finding is that analyses of intra-metropolitan commuting are mostly based on the central-city/ suburb dichotomy. Thus, this high level of geographical aggregation may conceal meaningful differences among commuters living in different neighborhoods. According to this author, when the magnitude of such variations is large, using central-city and suburban average researchers are probably overlooking some important spatial and social dimensions of commuting. More specifically, the circumstances of more disadvantaged population groups have often been underestimated.

Grengs (2010) identified four shortcomings in the literature when illustrating how policy-making is misguided by empirical studies of spatial mismatch: 1) scholars have been vague in defining the relevant independent variable in spatial mismatch studies, where the problem is accessibility rather than distance in itself; 2) ignoring the substantial difference between cars and public transit use for commuting; 3) studies are typically narrow when focused on specific groups (unemployed or low-wage African Americans living in the inner-city); and 4) the use of surprisingly simplistic geographical categories, i.e., the dichotomy central-city/suburbs. Besides, only a few studies have addressed these shortcomings. In the journey-to-work literature, study of social inequalities and exclusions has been integrated into the research lines described above by assessing unequal levels of access or travel times, and empirical studies have examined the differences among various groups considered at risk because of age, gender, socioeconomic condition, disabilities, etc.

Shen (1998) demonstrated that although location is very important, the key factor for low-income workers seeking employment opportunities is their transportation mode. In other words, although inner-city living offers a locational advantage for job opportunities, most inner-city residents do not own cars. This situation greatly limits available job opportunities for them in car-oriented US cities. Shen (2000) demostrated that in the 20 largest US metropolitan areas, commute times vary substantial and systematically among neighborhoods. This applies not only at a metropolitan level, but also for those located in the central city, demonstrating that commute times tend to be longer for low-income minorities than for other central city residents. Furthermore, in Shen's (2000) Boston case study, he proved that urban structure measured as a job accessibility factor is strongly related to commute times. From their studies of the San Francisco Bay Area, Kawabata and Shen (2007) demonstrated considerable inequality and temporal changes in job accessibility and commute times between people who use cars and those 
who use public transit, including locations within the metropolitan area. Results from their regression models indicate that greater job accessibility was significantly associated with shorter commute times for any mode of transportation used, but this degree of association was considerably greater for public transit than for car use. These results have been consistent in US auto-oriented cities. This is the reason why Kawabata and Shen assert that, in order to be able to make a systematic international comparison of the relationship between employment accessibility and commute times, we must first understand the nature of commute inequality between car and public transit use in metropolitan areas with different transport systems and urban spatial structures.

\subsection{Transport inequities in Latin America}

A wide body of literature describes Latin America's uncontrolled and unplanned urbanization, a process which has produced cities with strong social inequalities discernible in social segregation. The general depiction of this process can be found in the emerging peripheries produced by informal settlements, where the urban poor concentrate far from the urban centralities with a lack of suitable facilities and services (i.e., ONU HABITAT, 2008).

Latin American cities' urban periphery transportation problems are well known. Here is a literature review which sums up the main findings, without being very extensive. People face long expensive trips on multiple modes of public transportation to reach centrally located jobs (Vasconcellos, 2018; Guerra, 2017). In some cases, the formal transit system doesn't fill the demand. Therefore, different informality schemes lead to a complex interplay of formal and informal transport alternatives in travel choices (Cervero \& Golub, 2007). In large cities, sometimes wealthy suburbs develop into gated communities whose inhabitants become dependent on cars as a means of transportation (i.e., Vasconcellos's (2018) case of Brazil). In Mexico City's case, quality of public transit and road infrastructure decreases in a trend center-periphery with a significant variation in transportation fees due to discontinuity in metropolitan transit services (Flores-Espinosa, 2018). Such dynamic affects under-privileged groups disproportionately, restricting their accessibility from peripheral, often informal, settlements.

To tackle this problem, several cities have implemented massive transport initiatives such as Bus Rapid Transit and cable-way systems, the latter for hilly neighborhoods. Nevertheless, there still exist disparities both in access and mobility. Hernandez (2018) argues that, because Latin America mobility is unevenly distributed, it constitutes a field of contestation and dispute among social classes. Blanco, Lucas, Schafran, Verlinghieri, and Apaolaz (2018) refer to this as "contested mobilities" by associating and thus stressing the fact that in recent years, Latin America has emerged as a transport innovator and a place of important new urban contestations. According to these authors, the dynamic role of mobility interventions in shaping and reshaping Latin American cities' urban form has had uneven, unequal and often unfair social and economic outcomes for different population groups living and working within cities and their urban peripheries. Thus, the demand for world-class, central-city lifestyles incrementally pushes the poor to the urban periphery, where public transport services are increasingly in short supply. Actually, this process presents a problem not only for the rapidly developing Latin American cities, but also for developed and developing cities worldwide.

In the region, previous studies have mostly focused on evaluating area-level accessibility to jobs or other shopping, health and education opportunities (Moreno-Monroya, 2018; Hernandez, 2018; Figueroa, Hodgson, Mullen, \& Timms, 2018; Guzmán, Oviedo, \& Rivera, 2017). Accessibility analyses have also been used to evaluate the role of transport public policy in alleviating inequalities (Guzmán \& Oviedo, 2018; Guzmán, Oviedo, \& Cardona, 2018; Delmelle \& Casas, 2012; Bocarejo et al., 2014). Still another approach has been to estimate transport disadvantage indexes aimed at identifying district needs/supply shortfalls or spatial gaps to bring about transport system improvements (Pucci, Vecchio, 
Bocchimuzzi, \& Lanza, 2019; Jaramillo, Lizárraga, \& Grinlay, 2012). The main findings of this body of literature can be summed up in three main ideas: 1) An unequal transport supply and accessibility tends to favor the most affluent social groups by placing the urban poor in transport disadvantage (Figueroa et al., 2018; Delmelle \& Casas, 2012; Guzmán, Oviedo, \& Rivera, 2017); 2) Income is highly related to different mobility variables such as mobility assets possession, trip generation rates and differentiated use of modes of transportation (Blanco \& Apaolaza, 2018); and 3) Location (or territorial context) plays a key role in urban poor's disadvantage at making accessibility values to activities largely bound to the spatial distribution pattern of activities (Blanco \& Apaolaza, 2018; Guzman et al., 2018; Guzman et al., 2017; Delmelle \& Casas, 2012). In spatial terms, most studies remark that urban poor tend to locate in the peripheries, so they experience difficulties such as unsafety and transportation discomfort, especially since they face lengthy travel times because the highest concentration of opportunities (mainly jobs), infrastructure and public transport services locate in city central areas along the mass transit lines (for Brazilian cities see Vasconcellos (2018); for Santiago, Chile see Lukas \& López-Morales (2018) and Figueroa et al. (2018); for Medellin, Colombia, see Bocarejo et al. (2014) and for Bogotá see Guzman et al. (2017)). Some Global South literature has also tackled the analysis of disadvantaged groups using the spatial mismatch approach. For example, Bonomi and Amaral (2017) in Brazil did not find a clear relationship between different measures of accessibility to jobs and the probability of being unemployed. Nonetheless, they found a clear correlation in wages. As to observed travel times in Latin American, we need more research which allows us to explore its determinants, specifically as to the evaluation of the urban structure.

\subsection{Commuting in the MCMA}

The official geographical delimitation of the MCMA comprises municipalities in three states: Mexico City (CDMX, formerly Federal District), State of Mexico (SoM) and Hidalgo. There are 16, 59 and 1 municipalities per state respectively (Figure 1). 


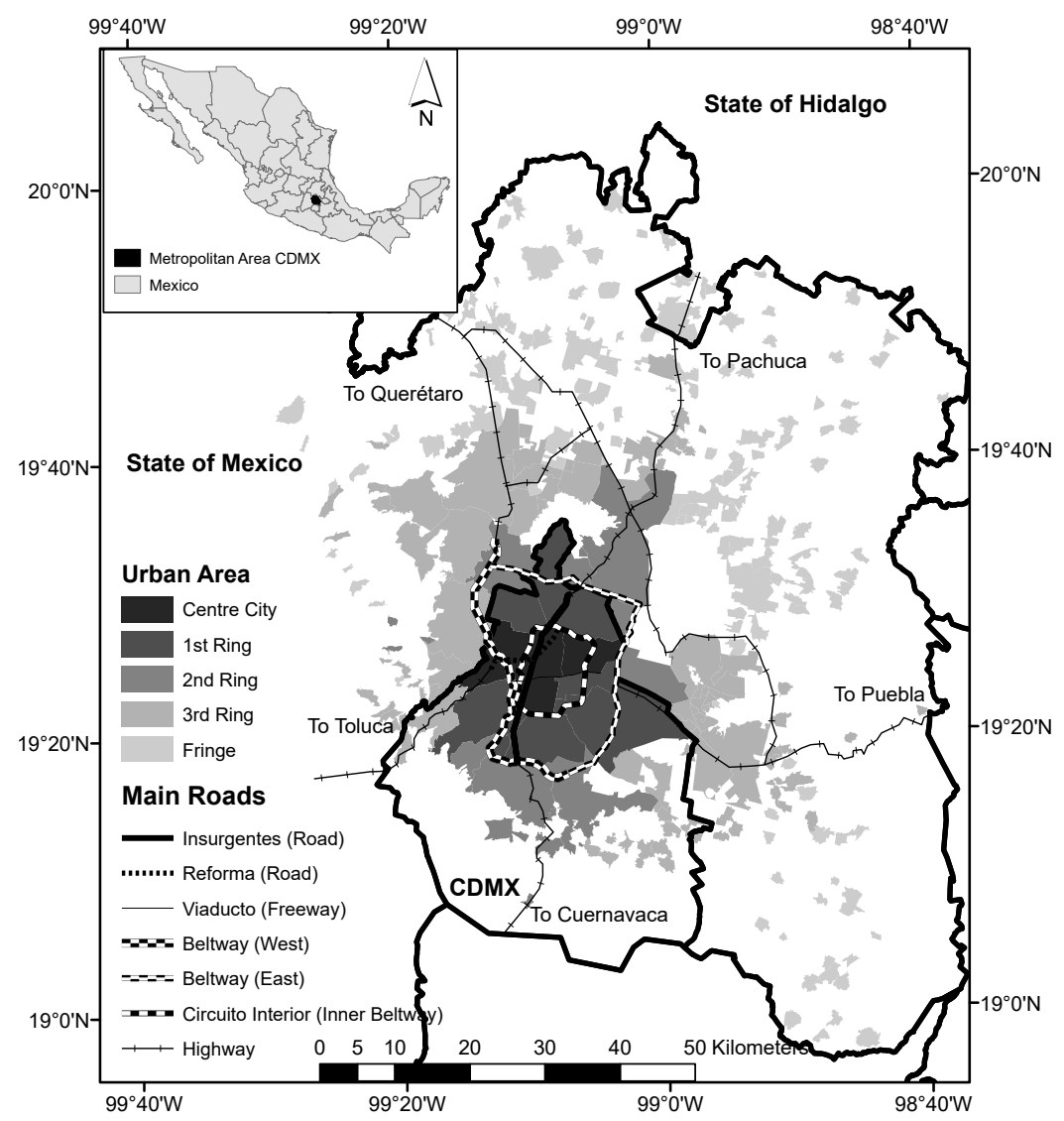

Figure 1. Main roads and urban rings

The MCMA does not have a consolidated polycentric urban structure yet (Montejano, Caudillo, \& Silván, 2016; Suárez \& Delgado, 2009), since it is dominated by a dispersed central area with a contiguous elongation through adjacent highways. Thus, the early stage of a polycentric urban structure entails a still highly influential central area. In order to understand the magnitude of this influence, we can compare central areas in similar size cities. Although this can be difficult because of the dissimilar criteria used to make such delimitations, it can also help to identify differences in urban structure. For example, a conservative estimation of the MCMA central area is $121.50 \mathrm{~km}^{2}$ (Casado, 2012). This cipher is approximately $27 \mathrm{~km}^{2}$ larger than the Los Angeles central area and 2.5 times larger than New York City central area, according to the estimations of the LA and NY central areas done by Glendening (2012). The NYC central area has also a metropolitan population similar to that of the MCMA. In terms of metropolitan share of employment, MCMA's Central Business District (CBD), as identified by Casado (2012), includes $32.7 \%$ of metropolitan employment, a superior percentage than that of NYC's CBD, which in 2000 was $21.2 \%$, as well as LA's, which was 13\% (Lee, 2007). Figure 2 illustrates the context map of socio-spatial patterns in aspects such as employment density, Economically Active People (EAP) density, Percentage of car ownership and Marginalization index. 


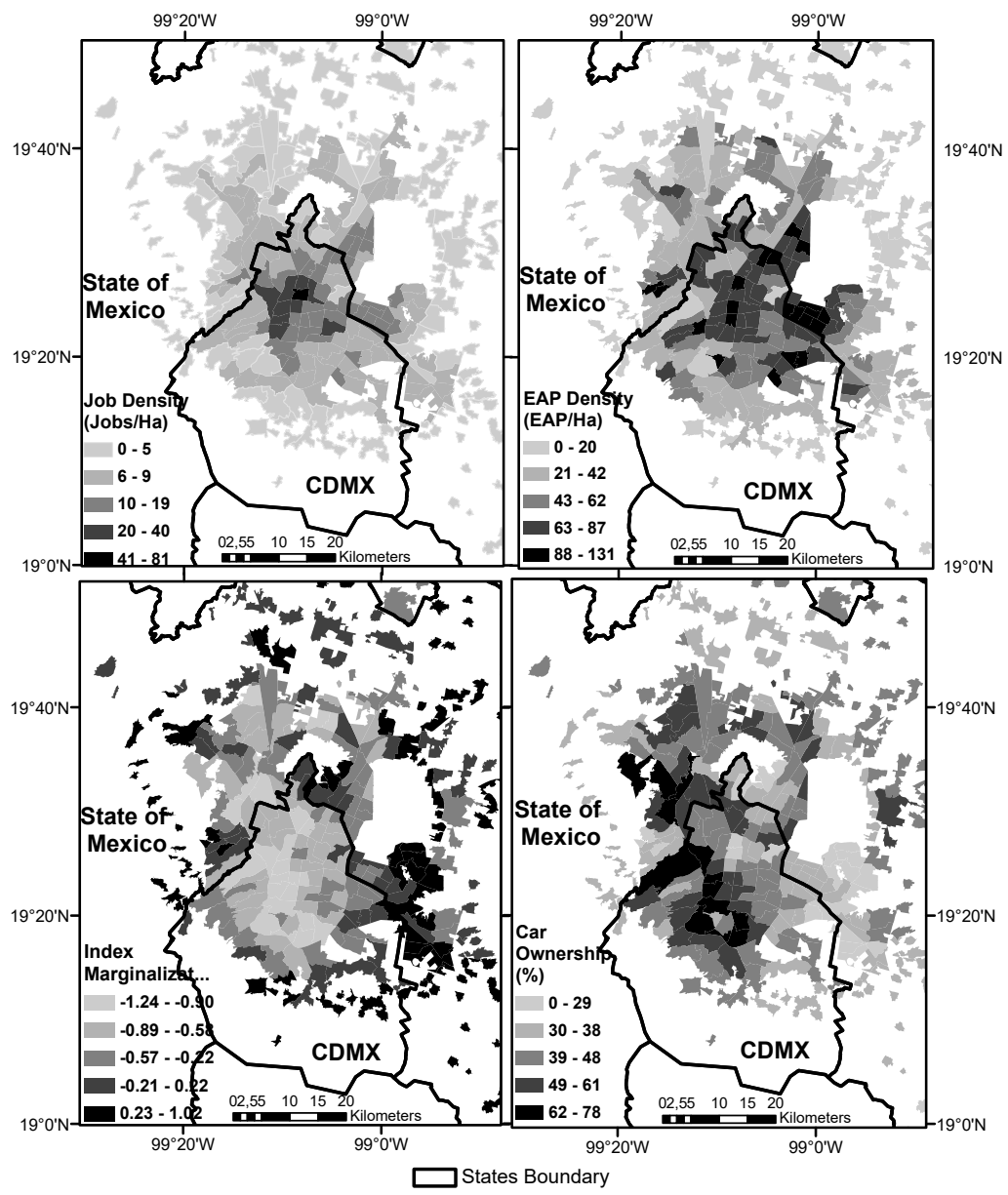

Figure 2. Socioeconomic geography in the MCMA. Geographic distribution of employment density (work trips attracted, top left), EAP density (top right), percentage of households car ownership (bottom left), marginalization index (bottom right).

Source: Authors' calculations using INEGI (2010) and Natural Breaks (Jenks) to determine map classes.

In the first decade of this century, Graizbord and Santillán (2005) and Duhau (2003) analyzed commuting flows at municipal level. Their conclusion was that the periphery has developed its own attraction coefficient, given that commutes to the central city are not overly intense or have become less so. However, most recent studies have pointed out that longer commutes from the periphery to the inner city are the overriding pattern. All studies that remark the huge influence of MCMA's CBD agree that, in this very imbalanced urban structure, most people living in the periphery must commute long distances (Montejano et al., 2016; Casado, 2012; Guerra, 2014). Thus, workers living in the CBD or in the subcenters make shorter trips in terms of distance and time than the average metropolitan commuter, and those living in the periphery and going to the CBD travel the longest distances. Suárez and Delgado (2009) found that the number of work trips to the central city has steadily increased in both absolute and proportional terms relative to the working population growth.

As described for many Latin American cities, Guerra (2017) argues that in MCMA, wealthier households price poorer households out of the most job-accessible central neighborhoods, forcing them to live in suburbs where the commute time gap between using a car and public transit is greater in favor of the former. Contemporary car ownership rates match income spatially, with car ownership being the highest in the slow-growing and wealthy western half of the city (Guerra, 2015). In relation to urban 
structure and commute times, Suárez, Murata, and Delgado (2016) measured commute times at municipal level and different income groups sensitivity in urban structure using two linear programming transportation models to evaluate the spatial mismatch between residential locations and places of work. Their results indicate that there is a strong relationship between residential location and place of work in the MCMA, with the urban structure comprising on average an $83 \%$ of commute times. Their results also prove that lower income groups are more sensitive to urban structure (a higher percentage of commute times is explained in the model) than other income groups. Thus, these groups must dedicate more effort to optimizing their work trips. Low-income workers have shorter commutes than other income groups living within the same area. This can be explained by the location of informal work activities, which seems to be a function of residential location of workers in the informal sector in response to the disadvantages of the housing and formal employment urban structure.

\section{$3 \quad$ Methods}

\subsection{Average one-way travel to work}

The spatial unit of analysis is the Traffic Analysis Zone (TAZ) from the 2017 Household Origin Destination Survey (HODS17), which subdivides the MCMA in 194 TAZs. This geographical unit stands in the middle of census tracts and municipalities. For the former, we find 5,648 tracts and 76 tracts for the latter, as described above. In Mexico City, a large municipality in the first ring can have up to 11 TAZs. However, in the outer part of the metropoly, one TAZ can include the urban area of one or more municipalities. The causes are both small population density and scattered settlements along the fringe. Overall, the geograhical extension of a TAZ remains closer to that of a municipio. HODS17-TAZ were the smallest area units for which all necessary data was available, as explained below. Nevertheless, it remains useful to identify nuances in the ACT differences among different areas in the inner city that the municipality could overlook.

Travel times come from two data sources. The first one is HODS17 itself (INEGI, 2017), where one-way Average Commute Time (ACT) was calculated for each TAZ at origin. In this survey, every movement from one place to another was recorded as a trip with a corresponding purpose in its destination. Thus, any trip with a work purpose was considered as a commute trip. Starting and ending times were recorded for each individual trip to work. Then the total time spent in the trip was calculated. Therefore, ACT includes any intermediate waiting time. In order to get the aggregated one-way ACT at TAZ-level, the information of each individual commute trip in the database is weighted by its corresponding expansion factor. In the HODS17, each trip is split by segments for each mode of transportation used. Individual legs within a trip are referred to as changing transportation modes, not as stops. Thus, a trip can have more than one mode of transportation, but in order to simplify, those made exclusively by car were labeled as car users while the rest were considered as transit users. Non-motorized travel (trips exclusively made by walking, biking or any combination of both) was dropped from the dataset. Trips considered started exclusively at peak hours (between 07:00 and 10:00 hours) and stayed within the metropolitan area. Thus, Transit users could include various combinations of transportation modes: collective, subway, Bus Rapid Transit (BRT), trolleybus, motorcycle, taxi, commuter train, light rail, cableway, bus, school bus and staff shuttlebus. A few trips considered as transit users could still have some individual leg of the trip made by car because they were considered as transit if the rest of the trip was made by any means of public transit. In addition to the ACT by TAZs, ACT estimates for each state were also calculated for comparison purposes.

The other source of travel time information used in this study was the region's travel demand 
model, TRANUS (model 2013, modeling date 25-02-2014), provided by ITDP (2014). The calibrated trip matrixes include travel times at peak morning hours between the region's $978 \mathrm{TAZ}$. However, these times were correlated into HODS17-TAZ by associating each HODS17-TAZ with the TRANUSTAZ that contains HODS17-TAZ's centroid in order to maintain congruency with the geographical unit of analysis selected for the present study. In the case of peripheral HODS17-TAZ for which the geographic centroid did not lie in an urban area, a correction was made to place the reference point in its corresponding central urban area. I used two travel time matrixes for this study: transit service and private car. Additionally, I extracted from HODS17 the work trips matrixes for car drivers and transit users that capture commuter flow between each pair of TAZ (INEGI, 2017) using the factor expansion of each trip. The ACT that was calculated using TRANUS data takes into account these inter-TAZ work trips. ACT values were displayed in a map and graphed according to distance to urban center in order to compare the resulting pattern among car and transit users.

\subsection{Regression models}

The dependent variable is one-way ACT, because it mostly affects quality of life and decisions about residential location for urban dwellers. Therefore, it is probably the best variable to identify any undue commute burden faced by certain population groups (Khattak, Amerlynck, \& Quercia, 2000). Thus, the dependent variable for a corresponding TAZ consists of the sum of commute flows between this and each of the other TAZs weighted by corresponding travel time divided by the total number of commuters in that TAZ. This yields a localized and standardized metric of travel costs. In the case of HODS17 data, this approach produced the same output that the average commute time of individual trips in each TAZ weighted by its corresponding factor expansion. Four dependent variables of ACT are analyzed separately: 1) TRANUS Car time, 2) TRANUS Transit time, 3) HODS17 Car time and 4) HODS17 Transit time. For each of these, three regression models were estimated: OLS and two spatial regressions, spatial lag model (Lag-ML) and spatial error model (Err-ML). All three models have the same set of covariates to allow direct comparison between them.

The initial step in a spatial analysis is to make a diagnosis of the univariate spatial autocorrelation in absence of covariates. This involves using global measurements of spatial dependence such as Moran's I statistics for continuous variables. For this analysis, neighboring HODS17-TAZ were set using first-order queen-based contiguity spatial weights and then, row-standardized in the contiguity matrix. When spatial dependence was diagnosed, the next step was to attempt to model this dependence with substantive covariates. There are two main sources of spatial dependence: 1) spatial diffusion, which occurs when spatially proximate units are influenced by the behavior of their neighbors and vice versa, and 2) geographic clustering of sources of the dependent variable, also called attributional dependence.

The first source is modeled via a spatial lag model while the second one is modeled via a spatial error model. A spatial lag model is estimated by maximum likelihood (ML), while spatial error dependence is estimated either by ML or by generalized method of moments (GMM). Thus, in the case of the remaining spatial dependence with covariates, a spatial diagnostic was applied to ensure that appropriate spatial model specifications were adopted according to the proposed approach (Anselin, 2005; Darmofal, 2015). The first step was to run the non-robust LMlag and Lmerror diagnostic tests, the results of which can lead to three different paths: 1) if none of these diagnostic tests determine the presence of spatial dependence, OLS estimates are suitable; 2) if only one of the diagnostic tests determined the presence of spatial dependence, the corresponding model should be estimated; 3) if both diagnostic tests determined the presence of spatial dependence, both the robust LMlag and the robust Lmerror diagnostic tests should be used, and the model used should be that with the higher value in these statistic tests.

Covariates in these models include the urban structure operationalized with an indicator of job ac- 
cessibility. The approach of assessing accessibility was based on the formula developed by Shen (1998), which is a variation of the Hansen Accessibility Index. This indicator captures the "demand side" of accessibility, that is, workers spatial distribution. The final equations are as follows:

$$
\begin{aligned}
A_{i}^{\text {auto }} & =\sum_{i=1}^{j} \frac{\mathrm{E}_{j} \mathrm{f}\left(C_{i j}^{\text {auto }}\right)}{\sum_{k}\left[\alpha_{k} W_{k} \mathrm{f}\left(C_{k j}^{a u t o}\right)+\left(1-\alpha_{k}\right) W_{k} \mathrm{f}\left(C_{k j}^{\text {transit }}\right)\right]} \\
A_{i}^{\text {transit }} & =\sum_{i=1}^{j} \frac{\mathrm{E}_{j} \mathrm{f}\left(C_{i j}^{\text {transit }}\right)}{\sum_{k}\left[\alpha_{k} W_{k} \mathrm{f}\left(C_{k j}^{\text {auto }}\right)+\left(1-\alpha_{k}\right) W_{k} \mathrm{f}\left(C_{k j}^{\text {transit }}\right)\right]}
\end{aligned}
$$

The travel impedance function is specified as $f(C i j)=e^{-b C i j}$, where $b$ is an empirically determined parameter. Based on a simple OLS regression (log of trips to work vs travel time), the estimated value for TRANUS time matrixes was -0.40 (TRANUS time was converted into minutes) and the value for HODS17 matrixes was -0.01. Time units are different in both types of matrixes, but focus was put in the pattern of relative differences within each HODS17-TAZ rather than the comparison of the absolute values of TRANUS and HODS17 data. Intra-zonal travel time was assumed to be 0.7 times the minimum travel time observed between each HODS17-TAZ. $E_{j}$ is the number of relevant employment opportunities in location $j ; A_{i}{ }^{v}$ is the accessibility available for people living in location $i$ and traveling by mode $v$; Cij is travel time from $i$ to $j ; W_{k}{ }^{m}$ is the number of people living in location $k$ and traveling by mode $m$ to seek relevant job opportunities; $f\left(C_{i j}{ }^{v}\right)$ and $f\left(C_{k j}{ }^{m}\right)$ are the impedance functions for transportation modes $v$ and $m$ respectively, which measure the spatial separation between $i$ and $j$, and $k$ and $j$, respectively. For an urban or regional system with $M$ transportation modes, $v, m=1,2, \ldots, M$, and $k$ locations, $k=1,2, \ldots, N$. For each dependent variable, the corresponding job accessibility indicator was used according to transportation mode and travel time source. One criticism to this method might be the fact that travel time is involved in both sides of the equation, i.e., in the average commute time and in calculating the job accessibility measure. However, this does not necessarily cause a relationship in the regression outcome, as seen in the results. The dependent variable reflects commute times taking into account actual commuter destinations, and the independent variable (job accessibility) reflects the potential reachable places to work. This approach has been employed by Shen (2000) and Kawabata and Shen (2007).

In the case of employment, trips to work attracted to each HODS17-TAZ were considered to be a proxy of total employment (formal + informal), an approach previously used by Suárez and Delgado (2009). The remaining socioeconomic variables were extracted from the 2010 socioeconomic census (INEGI, 2010). Values of the 2010 census tracts that lay within each of the HODS17-TAZ were added. Aggregating spatial data may introduce errors in the spatial analysis (known as modifiable areal unit problem), but the HODS17-TAZ were the smallest area units for which all the necessary data were available. EAP (economically active people per hectare) and Jobs (number of jobs per hectare) densities consider only urban areas, given that peripheral HODS17-TAZ includes non-urban land use, such as forests and agriculture. However, the urban area still considers a lot of non-residential land use. Therefore, these can be considered as gross densities.

I draw on a mixed land-use (MLU) index, estimated at block level by Montejano et al. (2016). This 
indicator ranges from 0 (concentration of one class of land use) to 1 (equilibrium between four land-use classes: residential, leisure, services and commercial). This indicator takes the centroid of each block and within, in a buffer of $500 \mathrm{~m}$, all economic units recorded in the census are counted (Montejano et al., 2016). Percentage of the block area within each HODS17-TAZ with an index value higher than 0.225 (percentile 75) was considered.

The other covariates are the presence of different percentages of socially disadvantaged groups: indigenous population, people with physical disabilities in terms of mobility and migrants (who arrived in the past five years). Thus, the specification of the regression models is complete according to Shen's (2000) recommendation, who stated that including socioeconomic variables and land use/urban structure variables together avoids possibly biased estimations and increases the explanatory power of the models as well.

Table 1. Variable descriptive statistics.

\begin{tabular}{|l|c|c|}
\hline \multicolumn{1}{|c|}{ Variable } & Mean & Standard deviation \\
\hline Dependent Variables & \multicolumn{2}{|c|}{} \\
\hline ACT Car - TRANUS (min) & 42.32 & 30.77 \\
\hline ACT Transit - TRANUS (min) & 88.64 & 8.98 \\
\hline ACT Car - HODS17 (min) & 49.06 & 13.0 \\
\hline ACT Transit - HODS17 (min) & 68.21 & 0.11 \\
\hline Explanatory variables & & 0.14 \\
\hline Employment Accessibility & & 0.13 \\
TRANUS - Car & 0.98 & 0.14 \\
\hline TRANUS-Transit & 0.68 & 27.49 \\
HODS17-Car & 0.86 & 36.95 \\
HODS17-Transit & 0.71 & 20.7 \\
\hline EAP Density (pop/ha) & 52.93 & 5.26 \\
\hline Job Density (jobs/ha) & 24.02 & 1.17 \\
\hline Mixed land use (\%) & 30.34 & 4.2 \\
\hline Percentage of Female Headed Households (\%) & 27 & 0.51 \\
\hline Percentage of illiterate population (\%) & 2.53 & 0.91 \\
\hline Percentage of migrants (\%) & 4.43 & \\
\hline Percentage of the physically disabled (\%) & 2.18 & \\
\hline Percentage of indigenous population (\%) & 1.59 & \\
\hline
\end{tabular}

\section{$4 \quad$ Results}

\subsection{Average commute times}

The general Average Commute Time in the metropolitan area is 63.03 minutes, being lower for Mexico City (59.01 $\mathrm{min}$ ) than the State of Mexico (67.21 min). The portion of the metroplitan area located in the state of Hidalgo is a very small peripheral area omitted in this comparison exactly for this reason. This well-known pattern among states is similar if it is disaggregated by transportation mode. Commute times by private car are always lower than commute times by transit (Table 2 ). 
Table 2. Average commute time (ACT, minutes) by gross geographical units (states) and transportation mode in 2017

\begin{tabular}{|l|c|c|c|}
\hline & MCMA & Mexico City & SoM \\
\hline General & 63.03 & 59.01 & 67.21 \\
\hline Car & 48.8 & 47.97 & 50.1 \\
\hline Transit & 68.47 & 63.65 & 73.08 \\
\hline
\end{tabular}

Source: Personal calculation based on HODS17 data (INEGI, 2017)

When looking at commuting times by transportation modes, we can see that lower commute times in Mexico City than in the State of Mexico are in part due to higher car usage in the former. Thus, State of Mexico is where people have the longest commutes (Table 3).

Table 3. Transportation mode choice for commuting in 2017 (Percentages)

\begin{tabular}{|l|c|c|c|c|c|c|c|}
\hline & Collective & Car & Subway & Walking & BRT & Taxi & Bicycle \\
\hline MCMA & 45.2 & 24.7 & 21.1 & 12.7 & 4.8 & 4.3 & 2.7 \\
\hline Mexico City & 38.7 & 27.5 & 24.1 & 12.1 & 5.7 & 5.3 & 1.9 \\
\hline SoM & 51.1 & 22.2 & 18.3 & 13.1 & 3.9 & 3.5 & 3.5 \\
\hline
\end{tabular}

Source: HODS17 report (INEGI, 2017)

Note: Sum of percentages is higher than $100 \%$ because some trips were made using more than one transportation mode.

However, commute times among Traffic Analysis Zones (TAZs) within each state are heterogeneous. In order to create a description of the geography of ACTs in the metropolitan area, it is first necessary to identify the periphery that is weakly linked to the metropolis. This primarily corresponds to what is called "the fringe" in Figure 3. Figure 3a illustrates this fringe as dark areas on the periphery. Here are the largest percentages of intra-TAZ trips to work, that is, people that remain within the TAZ for work purposes. This means that its functional relation with the rest of the metropolis is less intense. The fringe is mostly a semi-urban area that reflects leap-frog development in the urban sprawl process over the last decades. This periphery has fewer connections (the lighter shaded areas in the periphery in Figure $3 \mathrm{~b}$ ) because of the number of TAZ where people work.

Omitting the fringe, the remaining area can be considered to be the metropolitan region with more robust functional commute relationships. Here a central/east-west dichotomy can be detected. Those TAZ with more journey-to-work connections with other TAZs are located in the east (Figure 3b), while the areas with highest access to jobs are located in the inner city, mostly inside Mexico City (Figure 3c). The overall picture shows a pattern where people living further away from the urban center spend more time commuting. This fact was expected according to the neoclassical models of urban economics developed by Alonso (1964). 

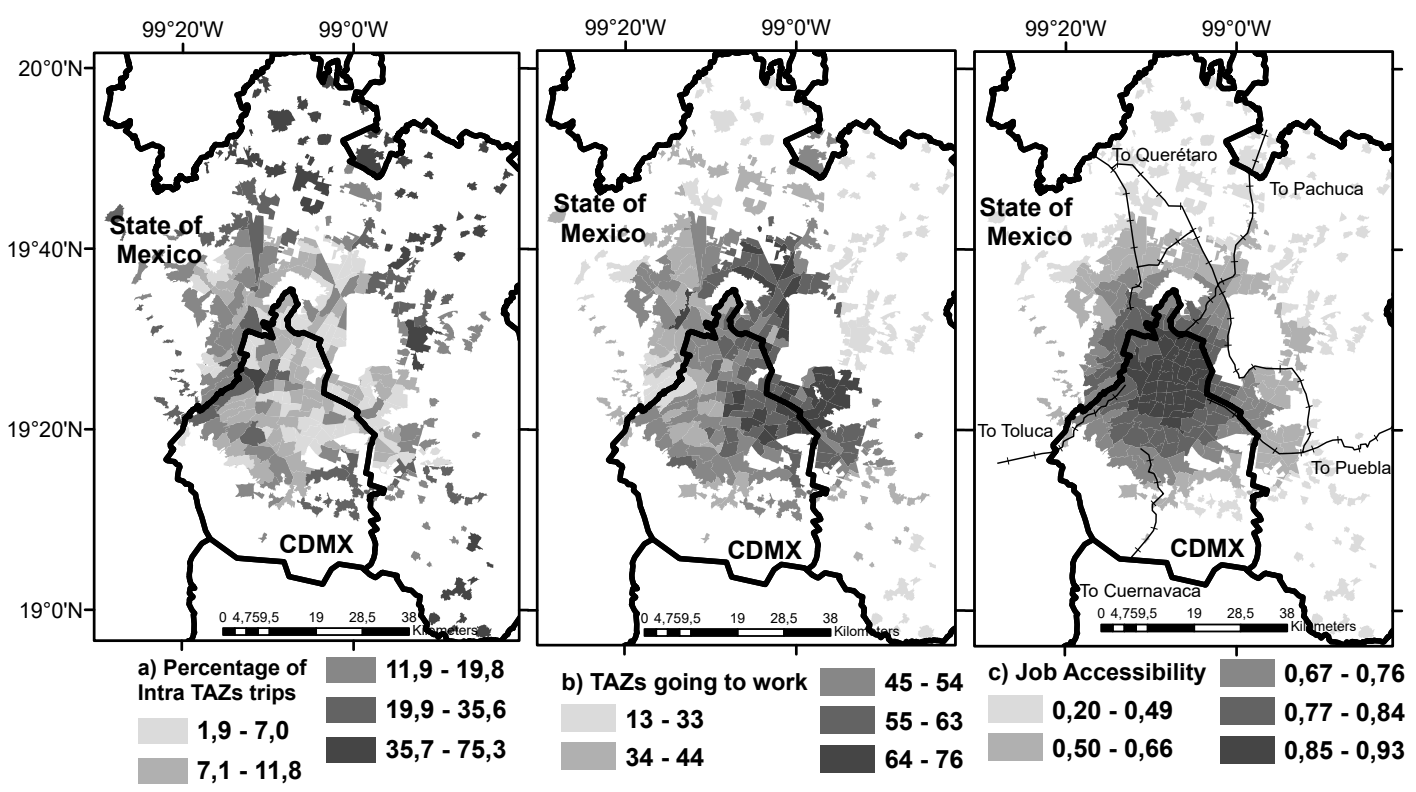

Figure 3. a) Percentage of intra-TAZ trips to work, b) Number of TAZ where commuters travel to work and c) Shen's-type job accessibility considering total employment
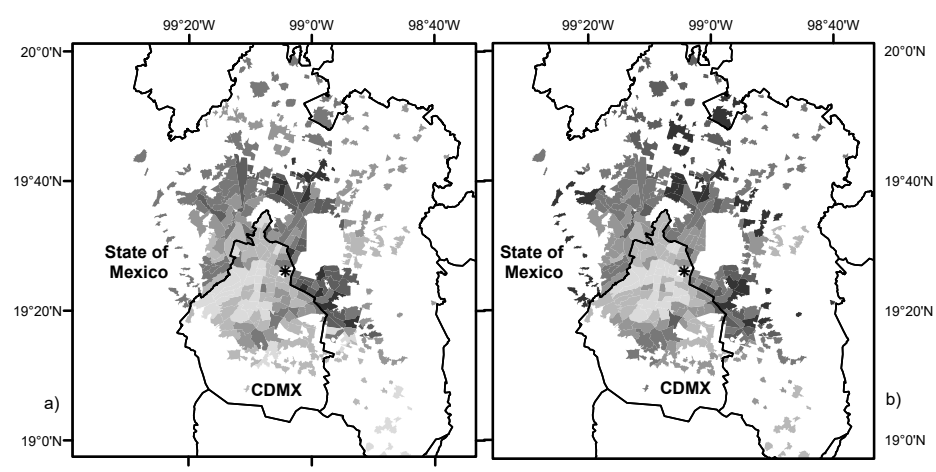

a) Car Tranus

b) Transit Tranus

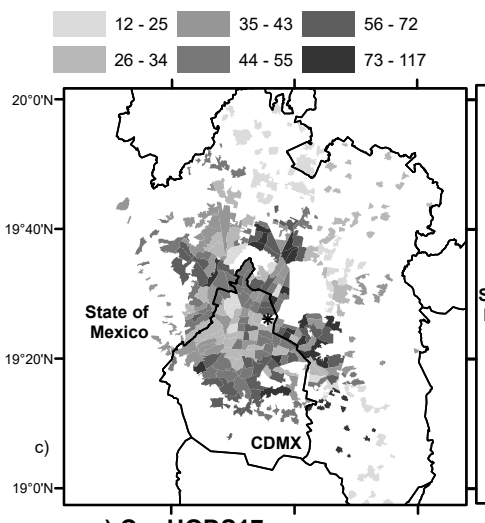

\begin{tabular}{|l|l|l|l|}
$35-54$ & $71-89$ & $112-134$
\end{tabular} $55-70 \square$
$\square 0-111 \square$
$\square$

c) Car HODS17

d) Transit HODS17

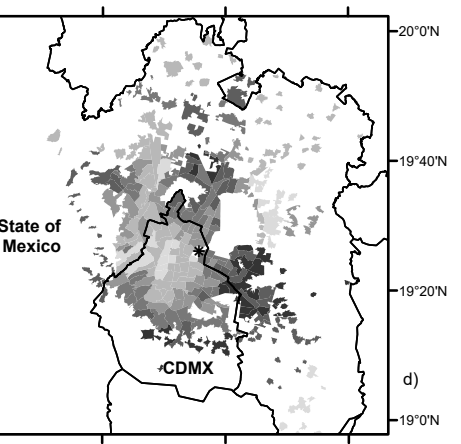

\begin{tabular}{|l|l|l|l|l|l|l|}
\hline $24-36$ & $45-48-60$ & $41-51$ & $60-67$ & $77-85$ \\
\hline $37-44$ & $49-54$ & $61-74$ & $52-59$ & $68-76$ & $86-100$ \\
\hline
\end{tabular}

Figure 4. Average commute time by car (a) and transit (b) according to the TRANUS model; and by car (c) and transit (d) according to HODS17.

Source: Authors' calculations using HODS17 (INEGI, 2017) and ITDP (2014) data 
Figure 4 shows ACT maps for car drivers and public transit users with TRANUS ( $\mathrm{a}$ and $\mathrm{b}$ respectively) and HODS17 data (c and d respectively). Natural breaks for each map are displayed in order for the geographical pattern to be easily identifiable, maximizing differences among categories. There are obvious differences between the two datasets. Overall, the value range is larger in TRANUS than in HODS17 data. In both datasets, ACT in the fringe is heterogeneous. The dark areas in the fringe are TAZ where ACTs are high, probably due to long trips going to other TAZ, although, as mentioned above, the proportion of those trips is small in comparison to those within the same TAZ. On the other hand, there are some clear areas in the fringe with low ACTs. As shown below, ACTs by car display a more random geography given the low spatial correlation. Also, there is a noticeable difference in the pattern of ACT by car in the periphery between both datasets.

There is a clear correspondence between the two datasets in the fringe area where ACT by transit is high, namely those darker areas in the north, west and east, and those with low ACT by transit in the northeast, southeast and northwest. ACT by private car is again highly random, especially in HODS17 data, with some slight identifiable TAZ clusters of high ACTs in the southeast, southwest and in the north. However, some central TAZ also suffer from high ACTs. This means that ACT by car varies among central city neighborhoods as well, and the causes of these differences between contiguous TAZ could be explained for various reasons, such as congestion effect, urban form and infrastructure, among others. In the TRANUS map, there is a noticeable area of low ACTs by car going from the center along to the southwest, probably due to fact that the best road infrastructure is located there. In the case of ACTs by transit, the lowest values are in the central area, given that the best transit infrastructure is here, where subway and Bus Rapid Transit systems are predominant. However, in the periphery, transit systems largely rely on inefficient semi-formal bus systems. Thus, the gap between ACT by car and ACT by transit is narrow in the central area.

There is a general noticeable inverted U-shaped pattern in the relationship between ACT by transit and distance to the urban center. ACT increases as the distance to the urban center increases, reaching a point where commute times decrease in the outer TAZs, probably due to unbearably high travel costs of traveling to the center. Since the best transit infrastructure is located in the inner city, low commute times in the center are explained. Additionally, there is less variation of commute times among centralcity neighborhoods (Figure $5 \mathrm{~b}$ and $5 \mathrm{~d}$ ). These aspects are consistent for both travel times datasets. The subway, also called Metro, as the most efficient mass transit system, has the higher density of stations per square kilometer in the central municipality. This follows that the quality of public transit and road infrastructure decreases in a trend center-periphery, with a significant variation in transportation fees due to discontinuity in metropolitan transit services, as described by Flores-Espinosa (2018). As we move towards the periphery, the semi-formal transport system of peseros or microbuses is the main mean of public transit (Table 3). Most of commute trips are made by microbuses. Peseros are small 2 nd-class buses with around 25 seats privately run by small operators. They organize themselves in pressure groups in order to influence the public transport fares determined by the central government. In the State of Mexico, the quality of these microbuses is even worse. Nevertheless, their fare is considerably higher. Thus, these graphs (Figure 5) show the increasing disadvantge of living in the periphery, especially if we consider that the number of work trips to the central city has steadily increased in both absolute and proportional terms relative to the working population growth (Suárez \& Delgado, 2009). This has not been mitigated by some employment subcenters which have developed outside the city center.

As to low ACT in the extreme periphery and the metropolitan fringe, these are not necessarily good news, since this area has no employment opportunities, as can be seen in Figure 2. We can interpret a forced condition of low mobility only to the surroundings to look for available jobs. The living expectations might rely mostly on the semi rural local production with low opportunities to compete in the 
inner city arena for available jobs. Public policies should try to flaten the curve by considering high ACT areas in the first and second metropolitan ring.

The pattern is different when commuting by car. TRANUS data still shows that ACT times and their variation increase as the distance to the center increases, while in the outer TAZs, commuting times decrease. However, there is no noticeable curve, though there is one outlier around $12 \mathrm{~km}$ away from the urban center. These ACTs by car with HODS17 show a flat pattern with a slight decrease in the outer TAZs. No noticeable curve in commuting time exists even within $30 \mathrm{~km}$ from the urban center, which indicates the inner-city does not necessarily offer an advantage. On the contrary, a congested environment limits car mobility.

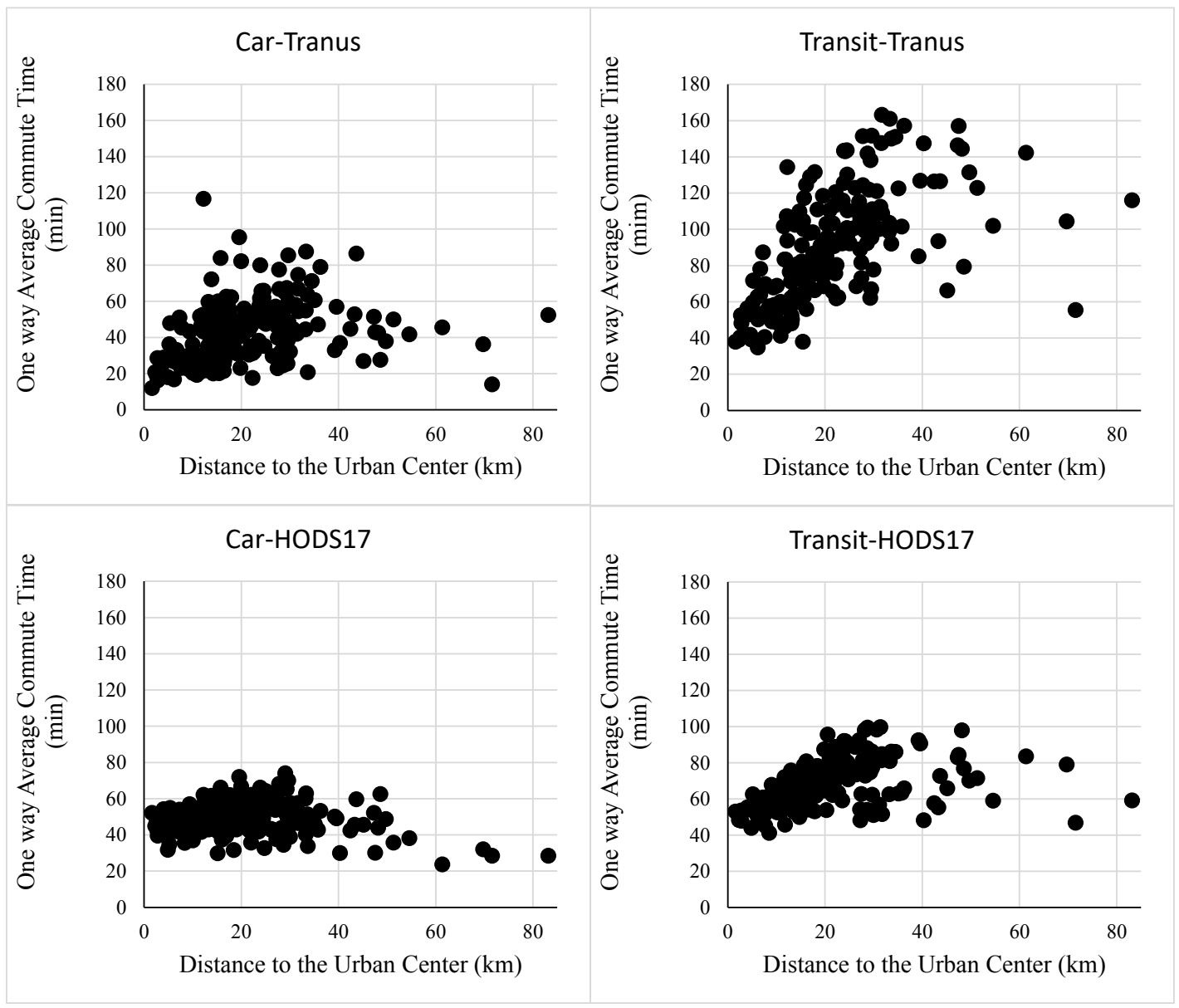

Figure 5. Average commute time by car (a) and transit (b) according to the TRANUS model; and by car (c) and transit (d) according to HODS 2017.

Source: Authors' calculations using HODS17 (INEGI, 2017) and ITDP (2014) data

Moran's statistic confirms the existence of a positive spatial autocorrelation for the four variables under examination. Using TRANUS data, this indicator is 0.55 and 0.65 for ACT by car and public transit respectively. In the case of HODS17 data, Moran's I is 0.67 for transit users, but for car users such spatial correlation is of less magnitude with a statistic of 0.18 (Table 4). 
Table 4. Univariate (dependent) spatial autocorrelation detection

\begin{tabular}{|c|c|c|c|}
\hline Variable & Moran's I & $\begin{array}{c}\text { Moran's I test } \\
\text { p-value }\end{array}$ & $\begin{array}{c}\text { Permutation test } \\
\text { p-value }\end{array}$ \\
\hline ACT by Car (TRANUS) & 0.5544 & $<2.2 \mathrm{e}-16$ & 0.01 \\
\hline ACT by Transit (TRANUS) & 0.6516 & $<2.2 \mathrm{e}-16$ & 0.01 \\
\hline ACT by Car (HODS17) & 0.1828 & $6.419 \mathrm{e}-05$ & 0.01 \\
\hline ACT by Transit (HODS17) & 0.67 & $<2.2 \mathrm{e}-16$ & 0.01 \\
\hline
\end{tabular}

Note: ACT (average commute time). Airport tract was dropped from this analysis.

Table 5 presents the results of the spatial diagnostic test, which can be used to identify the nature of spatial autocorrelation. With TRANUS data for commuting by car and transit models, both non-robust tests indicated a spatial dependence with the presence of covariates. However, for commuting by car, the results of the robust versions of the diagnostic tests are not significant at 5\% level. Only the LMlag test is significant at $10 \%$ level. In this case, $\mathrm{LM}_{\text {lag }}$ is the correct specification. In the transit model case, the error model is the correct specification, since only the $\mathrm{LM}_{\text {err }}$ test in the robust version is statistically significant at 0.05 . With HODS17 data, the non-robust $\mathrm{LM}_{\text {lag }}$ test for car users and both non-robust versions for transit users are statistically significant at 0.05 . In the robust versions, only $\mathrm{LM}_{\text {lag }}$ test is significant at 0.05 , which demonstrates that the lag model is the correct specification for car drivers and transit users using HODS17.

Table 5. Autocorrelation tests for OLS residuals

\begin{tabular}{|l|l|l|l|l|l|l|l|l|}
\hline \multicolumn{7}{|c|}{ TRANUS } & HODS17 \\
\hline Test ACT- Car p-value & $\begin{array}{l}\text { ACT- p-value } \\
\text { Transit }\end{array}$ & ACT-Car p-value & $\begin{array}{l}\text { ACT- } \\
\text { Transit }\end{array}$ & p-value \\
\hline Total Employment & & & \\
\hline LM (lag) & 11.13 & 0.0008 & 6.20 & 0.012 & 3.96 & 0.046 & 87.66 & $2.2 \mathrm{e}-16$ \\
\hline Lm (error) & 8.78 & 0.003 & 10.85 & 0.0009 & 2.20 & 0.137 & 77.28 & $2.2 \mathrm{e}-16$ \\
\hline Robust LM (lag) & 2.95 & 0.0854 & 0.287 & 0.591 & 4.58 & 0.032 & 11.33 & 0.0007 \\
\hline Robust Lm (error) & 0.607 & 0.4359 & 4.937 & 0.026 & 2.82 & 0.092 & 0.95 & 0.327 \\
\hline
\end{tabular}

\subsection{Regression analysis}

An exploratory analysis with the OLS model was performed using all covariates initially considered in order to identify multicollinearity and to select the best possible specification. Some variables were removed from the analysis given the high correlation between socioeconomic covariates. For example, the inclusion of an index of marginalization, which is a composite index calculated by the governmental Agency of Population Affairs based on census variables, results in high collinearity. The census does not record income. The job accessibility index using the Shen (1998) methodology is highly correlated with distance to the center. High correlation between covariates is problematic since this collinearity results in estimation bias. Therefore, in order to avoid this, the distance to the center variable was removed from the model. The percentage of female workforce and the percentage of population with post-basic education also resulted problematic when included in the models, according to the variance inflation factor test which quantifies the severity of multicollinearity (values higher than 10). Thus, these two percentages were deleted as well. However, the final specification still considers enough variables to study the urban structure and socioeconomic aspects of commuting in the Mexico City Metropoltan Area. 


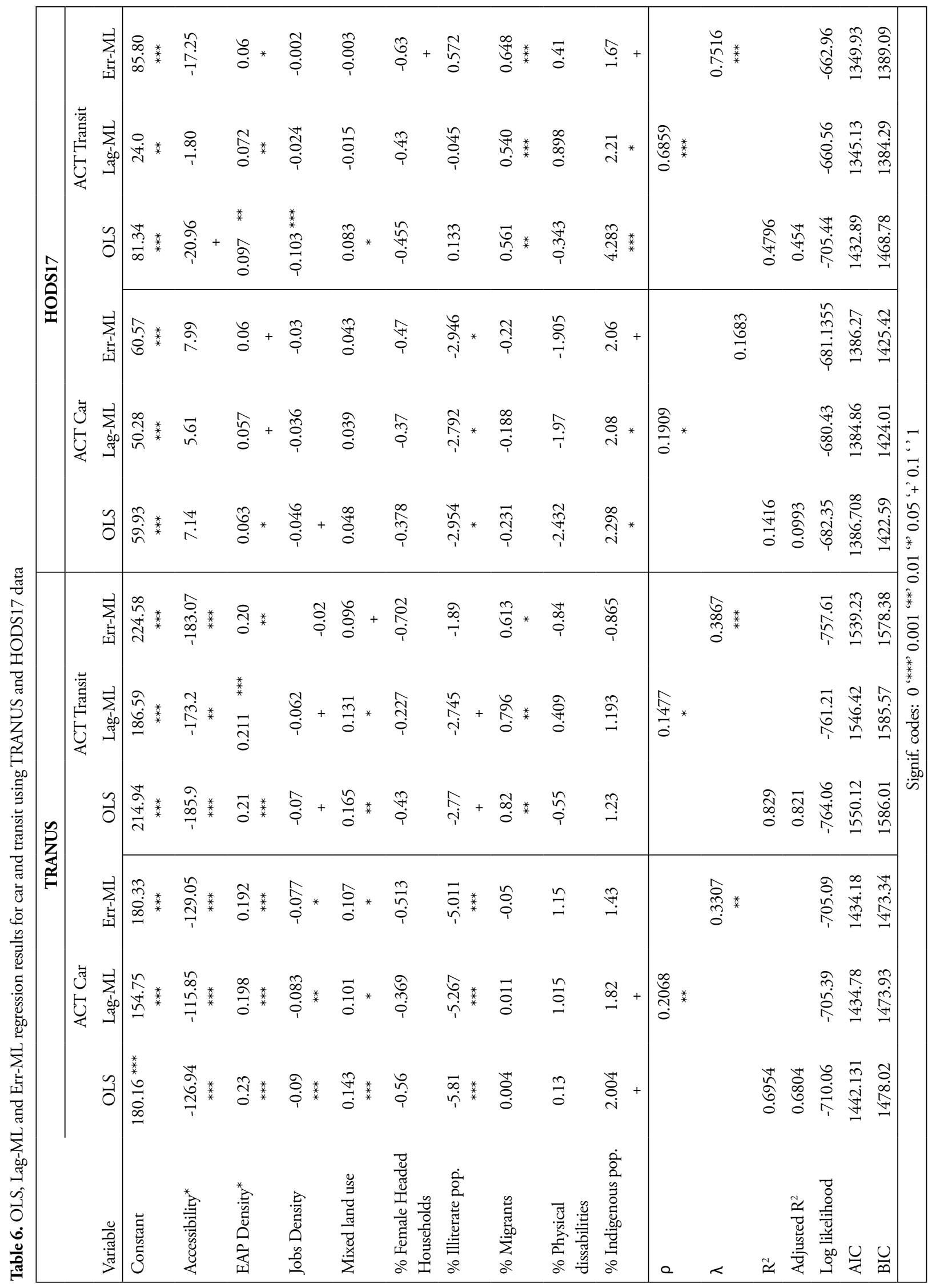


Table 6 presents regression results from the ACT models by driving alone and public transit with TRANUS and HODS017 data. The table also reports the goodness of fit indicators: $\mathrm{R}$ and $\mathrm{R}^{2}$ values for OLS, as well as the log-likelihood, Akaike Information Criterion (AIC) and Bayesian Information Criterion (BIC) values for the three regressions models, OLS, Lag-ML and Err-ML. A higher log-likelihood value and lower $\mathrm{AIC}$ or $\mathrm{BIC}$ values suggest a better fit.

The Lag-ML and Err-ML regressions provide similar fit for the car model with TRANUS data. The respective rho $(\rho)$ and lambda $(\lambda)$ coefficients are significant at 0.01 level. Although, as mentioned earlier, the Lag-ML model is the correct specifiction for car users with TRANUS information, so result description will focus on it. In the case of public transit with TRANUS, Err-Ml regression provides the better fit in congruence with the correct specification as explained above. The lambda $(\lambda)$ parameter is highly significant $(\mathrm{p}<0.001)$. In the analysis with HODS17 data for car users, the Lag-ML model seems to have better fit according to Log likelihood and AIC, although with OLS regression BIC performs better. The rho coefficient from the Lag-ML model shows significance at $5 \%$, with the lambda parameter of the Err-ML model not being statistically significant. In the case of commuting by transit, the Lag-ML regression has a better fit with any of the indicators (log-likelihood, AIC and BIC) with a significant $\rho$ coefficient ( $\mathrm{p}<0.001$ ). Thus, the following analysis is focused on highlighting the main findings from the Lag-ML regression, comparing it with the other two models (OLS and Err-ML) when necessary for a better interpretation.

In the model using TRANUS data, after controlling for other variables related to the urban spatial structure (Economically Active People density and jobs density) and socioeconomic aspects, job accessibility has a significant inverse association $(\mathrm{p}<0.001)$ with ACT for car drivers as well as for transit users. The degree (represented by coefficients) was higher for public transit commuters than for car commuters with TRANUS data. For example, a unit increase in access entails a decrease of 115.8 and 183 minutes in commute times using car and public transit respectively. In terms of direction (sign) and significance, these findings are consistent with the literature for US cities. In his study of Boston, Shen (2000) found that general access and general one-way commute times are inversely associated: a decrease of 4.5 minutes for every one unit increase in general access. In their study of San Francisco, Kawabata and Shen (2007) also found an inverse and significant association of job access and commute time, which is considerably greater for public transit use than for driving a car, with the coefficient being -9.1 and -3.2 respectively for the year 2000. The relative high magnitude of the coefficient for the Mexico City Metropolitan Area could be due to a wide range of modeled times in TRANUS. On the other hand, this coefficient makes sense if we consider that a unit increase (or decrease) of access is considered to entail almost the entire range of observed access values (see Table 1).

When using HODS17, job access is not statistically significant with any spatial regression models, not even OLS in the case of commute times for car drivers. Likewise, spatial regression models fail to detect a significant inverse association between job accessibility and ACT for transit commuters. Only in the case of OLS, there is a weak significance at $10 \%$, where a one unit increase in job accessibility leads to a decrease of 20 minutes in ACT. The disconnection between observed ACT and job accessibility raises two not mutually exclusive interpretations. First, there is an effect of the metropolitan fringe where there are TAZs with low access and low ACT. The fringe is a semi-urban area where rural life styles are prominent, and an important share of people is employed in agriculture. Urban jobs would be difficult to reach given the high cost of traveling to the inner city. I hypothesize that the expected inverse relationship between ACT and job access would be identifiable if dropping the fringe from the analysis. Likewise, there could exist different associations between job access and ACT according to different geographical subregions in the metropolitan area. Second, it seems that there is a congestion effect in those areas with high access and high ACT. This means that there are jobs-rich areas that are not connected 
by efficient and rapid mass transit systems, such as the subway. Instead, people still rely in an inefficient semi-formal minibus service. This is the case for employment subcenters to the west and south of the metropolitan area. From a public policy perspective, this disconnection would not mean to discard job access as a way to reduce ACT. Rather, this is why transport public policy must intensify this relationship through physical planning policies that bring opportunities closer to areas where workers that have to take long trips reside. Job access shows a location effect because this indicator has a negative linear relation with respect to distance to the metropolitan center at Traffic Analysis Zones (TAZs) level. Thus, including distance to the urban center would be collinear with job access. In the case of jobs density, relationship with distance to the urban center is a negative exponential curve. Job access and jobs density do not necessarily have the same effect on travel behavior. For example, job access is positively associated with increased complexity of travel for transit commuters, while jobs density favors simple tours. None of these variables affects trip chaining for car drivers (Bautista-Hernández, D., 2020).

Using TRANUS data, Economically Active People has a significant and positive association with commute time for driving alone and for public transit commuters. The magnitude of the association is similar for both transportation modes. One unit increase in EAP density increases ACT by $0.2 \mathrm{~min}$. Using HODS17 data, EAP still holds a significantly positive relation with ACT in both transportation modes, with weak significance for car (at 10\%) and higher significance for transit commuters (at $1 \%)$. The magnitude of this relationship is lower with HODS17 than with TRANUS, where one unit increase in EAD density increases 0.072 min ACT by transit. Kawabata and Shen (2007) found that in San Francisco there was a positive relation of population density and commute times by car, whereas the relation was inverse for commutes by transit. This is explained as the effect of traffic congestion that slows travel speeds by car. The inverse relation of transit happens because the transit system service is usually better in locations with higher population densities. Nevertheless, in the case of MCMA, there might be a congestion effect for both modes of transportation.

Jobs density is associated with shorter commutes for car drivers using TRANUS data. In other words, commute time by car decreases $0.083 \mathrm{~min}$ as jobs density increases one unit. However, there is no significant association for transit users in the Err-ML regression, as in the case of HODS17 data with both transportation modes and both spatial regression models. In these cases, only OLS regressions seem to detect that negative association between jobs density and ACT. This apparent disconnection of ACT by transit with jobs density would suggest a mismatch between nearby available jobs and potential skilled workers to fill this labor force demand.

Mixed land use shows a positive association with ACT by car and transit with TRANUS data, being significant at 0.05 and 0.1 levels, respectively. One percent increase means an increase of $0.1 \mathrm{~min}$ and $0.09 \mathrm{~min}$ of commute time for car and transit respectively. This association is difficult to explain, but it could be explained with an effect of congestion, as in the case of EAD density. The effect of other mixed land-use indicators remains to be tested as a future research line. This positive association between ACT and mixed land use is not consistent with HODS17, where none of the spatial regression models detects any association.

The proportion of female headed households is not associated with ACT in any transportation mode. None of the regression models with any travel time data was able to detect any significant association. These results do not show this group as having any spatial relation with the patterns of metropolitan commute time. However, a further analysis of a group formed by the combination of female headed households and low income populations could be of interest, since it could offer a different picture.

An increase in the proportion of illiterate populations is significantly associated with a decrease in commuting time by car. TRANUS data indicates that a $1 \%$ increase in the share of illiterate population is associated with a 5.2 minutes decrease in this car commuting, while this reduction is of 2.7 minutes 
when using HODS17 data. The proportion of illiterate population has weak significance (at 10\%) for commuting by Transit with TRANUS data. However, there is no significant association with HODS17 data.

An increase in the proportion of migrants is significantly associated with an increase of ACT by public transit. This increment is of 0.61 and 0.54 minutes, according to TRANUS and HODS17 data respectively, for every one percentage increase in the share of residents living in a different state in 2005 (five years prior to the census year). The situation of migrant workers can be considered to be a fairly consistent effect that reflects the problem of affordable housing close to job centers. This causes recent migrants to reside far from employment locations. It is an indication of the need for more public transit in peripheral areas where the largest percentages (by TAZ) of this population group reside.

The percentage of people with physical disabilities is not statistically significant (at the $5 \%$ level) with any model, dataset and transportation mode. Thus, the metropolitan geography where this group lives does not appear to be linked with the ACT metropolitan pattern.

An increase in the proportion of indigenous populations is positively associated with ACT by driving alone. This association has weak significance (10\%) with TRANUS, but with HODS17, it turns out to be significant at 5\%. According to TRANUS, $1 \%$ increase of indigenous population is associated with an increase of $1.82 \mathrm{~min}$, while for HODS17, the ACT increase is of $2.08 \mathrm{~min}$. In the case of ACT by public transit, the positive association is significant with HODS17 (5\%). The ACT increase is of about 2.21 minutes every $1 \%$ increase in the share of indigenous residents. I interpret this as a sign of disadvantage in transport for this group due to urban structure. Therefore, the design of transportation programs directed to help this population group is a public policy worth exploring. Public investment in TAZs with high percentage of indigenous people should be made a priority under principles of equity.

\section{Conclusions}

The intra-metropolitan geography of ACT clearly shows a highly unequal city in the experiences of journeys-to-work. ACT is lower for car drivers than for transit users in each TAZ, although the gap is wider in TRANUS than the disparity in HODS17 data. After identifying the periphery that is weakly linked to the rest of the metropolis, what can be detected is a central/west-east dichotomy. Those TAZ with more journey-to-work connections with other TAZ are located in the east, while job-rich areas are located on a north-south axis slightly positioned towards the west side with clear elongations along highways flowing towards the cities of Queretaro and Toluca. Overall, the relationship between ACT by

transit and distance to the urban center form an inverted U-shaped curve. Commuting times increase as the distance to the urban center increases, reaching a point where commute times decrease in the outer TAZs. Conversely, the relationship between ACT by car and distance to the center shows a semi flat pattern with a slight decrease in the outer TAZs.

A strong spatial correlation was detected in ACTs for both car drivers and public transit users. However, for the former, the magnitude was lower in HODS17 data according to Moran's statistic. The Lag-ML regression is the correct specification for ACT by car with TRANUS and HODS17, as well as for ACT by Transit with HODS17. On the other hand, the Err-ML regression is the correct specification for ACT by Transit with TRANUS.

After controlling for other variables related to urban spatial structure and socioeconomic aspects, job accessibility plays a significantly inverse role in determining ACT for transit users and for car users using travel times from TRANUS. Overall, the degree represented by coefficients and significance of job access is higher in ACT by transit users than for car drivers in the three regressions. However, this response in not consistent using observed travel times from HODS17, where the significance for 
transit users is weak $(\mathrm{p}<0.1)$ in the OLS regression and not significant in the Lag-ML regression. The main policy implications are to use job access as a way to reduce ACT, thus intensifying this relationship through physical planning policies that bring opportunities closer to areas where workers have to take long trips. Additionally, it is of great importance to keep building subway lines for those routes for which BRT systems cannot be substitutes, though this has not been the case over the past two decades.

Other covariates were also significant using TRANUS. EAP density is positively associated with ACT by driving alone and for transit commuters. The jobs density is negatively associated with ACT by car, while the significance is weak in the case of transit users. Mixed land use is positively associated with ACT by both car drivers and public transit users.

Using HODS17 data, the association between ACT and urban form variables was not robust. There is only one result of importance: the positive association between EAP density with ACT by car (at $10 \%$ ) and public transit (at 1\%). Job access does not have a consistent response for ACT with any of the two transportation modes. Longer commute times do not appear to be associated with proportions of population groups such as female headed households, illiterate population or people with physical disabilities. On the other hand, a consistent result using TRANUS and HODS17 is that an increase in the proportion of migrants is significantly associated with an increase of ACT by public transit. Moreover, according to HODS17, an increase in the proportion of indigenous populations is positively associated with ACT for both car drivers and public transit commuters.

It is important to point out the limitations of this study. The precision of travel time data sources is of special importance. Travel times in TRANUS and HODS17 data are substantially different. Modeled times should include data not only from travel surveys, but also from periodic measurements on the levels of service in transportation infrastructure in order to offer a more realistic panorama of average travel time between TAZs. Thus, it is strongly recommended that the metropolitan transportation agency, COMETRAVI, collects and maintains reliable longitudinal information for a more thorough analysis in the evolution of commuting in the MCMA.

\section{Acknowledgements}

I would like to express my deep gratitude to Mr. Ulises Navarro (ITDP-México) and Dr. Seth Contreras for kindly sharing information about the application of the transport model(TRANUS) in MCMA. I would also thank Dr. Camilo Caudillo (CentroGeo) for kindly sharing a database about mixed land use. 


\section{References}

Alonso, W. (1964). Location and land use. Cambridge, MA: Harvard University Press.

Anselin, L. (2005). Exploring spatial data with GeoDaTM: A workbook, revised version. Santa Barbara, CA: Center for Spatially Integrated Social Science. Retrieved from www.csiss.org/

Bautista-Hernández Dorian, A. (2020). Job accessibility, commuting time and travel complexity in the México City Metropolitan Area (MCMA) (PhD dissertation). Seattle, WA: University of Washington.

Benevenuto, R., \& Caulfield, B. (2019). Poverty and transport in the global south: An overview. Transport Policy, 79, 115-124.

Blanco, J., \& Apaolaza, R. (2018). Socio-territorial inequality and differential mobility. Three key issues in the Buenos Aires Metropolitan Region. Journal of Transport Geography, 67, 76-84.

Blanco, J., Lucas, K., Schafran, A., Verlinghieri, E., \& Apaolaz, R. (2018). Editorial: Contested mobilities in the Latin American context. Journal of Transport Geography, 67, 73-75.

Bocarejo, J. P., Portilla, I J., Velásquez, J. M., Cruz, M. N., Peña, A., \& Oviedo, D. R. (2014). An innovative transit system and its impact on low-income users: The case of the Metrocable in Medellín. Journal of Transport Geography, 39, 49-61.

Bonomi, A., \& Amaral, E. H. (2017). Spatial mismatch, wages and unemployment in metropolitan areas in Brazil. The Journal of ERSA. 4(3), 175-200.

Casado, I. J. M. (2012). La estructura policéntrica de los mercados laborales locales de la zona metropolitana del Valle de México. Investigaciones Geográficas, Boletín del Instituto de Geografia UNAM, 79, 97-118.

Cervero, R. (1989). Jobs-housing balancing and regional mobility. Journal of the American Planning Association, 55(2), 136-150.

Cervero, R., \& Golub, A. (2007). Informal transport: A global perspective. Transport Policy, 14 (6), 445-457.

Cervero, R., \& Landis, J. (1992). Suburbanization of jobs and the journey to work: A submarket analysis of commuting in the San Francisco Bay Area. Journal of Advanced Transportation, 26(3), 275-297.

Cervero, R. (1996). Jobs-housing balance revisited: Trends and impacts in the San Francisco Bay Area. Journal of the American Planning Association, 62(4), 492-511.

Darmofal, D. (2015). Spatial analysis for the social sciences. In Analytical methods for social research. Cambridge, UK: Cambridge University Press.

Delmelle, E. C., \& Casas, I. (2012). Evaluating the spatial equity of bus rapid transit-based accessibility patterns in a developing country: The case of Cali, Colombia. Transport Policy, 2, 36-46.

Duhau, E. (2003). División social del espacio metropolitano y movilidad residencial. Papeles de Población, 9(36), 161-210.

Figueroa, M. C., Hodgson, F., Mullen, C. \& Timms, P. (2018). Creating inequality in accessibility: The relationships between public transport and social housing policy in deprived areas of Santiago de Chile. Journal of Transport Geography, 67, 102-109.

Flores-Espinosa, M. A. (2018). ¿Cómo se mueven los pobres? Dificultades en la movilidad de la periferia sur de la Zona Metropolitana de la Ciudad de México. In A.G. Aguilar \& I. Escamilla (Eds.), Pobreza y exclusión social en ciudades Mexicanas. Dimensiones socioespaciales (pp. 357-294). México City: Porrúa and Instituto de Geografía UNAM.

Giuliano, G. (1991). Is jobs-housing balance a transportation issue? Transportation Research Record, 1305, 305-312.

Giuliano G., \& Small, K. A. (1993). Is the journey to work explained by urban structure? Urban Studies, $30,1485-1500$. 
Glendening, K. S. (2012). Delimiting the postmodern urban center: An analysis of urban amenity clusters in Los Angeles (MSc Dissertation in Geographic Information Science and Technology). Graduate School University of Southern California, Los Angeles.

Gordon, P., Richardson, H., \& Jun, M. J. (1991). The commuting paradox: Evidence from the top twenty. Journal of the American Planning Association, 57(4), 416-420.

Gordon, P., \& Bumsoon L. (2015). Chapter 6: Spatial structure and travel: Trends in commuting and noncommuting travels in US metropolitan areas. In R. M. Hickman, D. Givoni, D. Bonilla \& Banister (Eds.), Handbook on transport and development. Cheltenham, UK: Edward Elgar.

Graizbord, B., \& Santillán, M. (2005). Dinámica demográfica y generación de viajes al trabajo en el AMCM: 1994-2000. Estudios Demográficos y Urbanos, 58, 71-101.

Grengs, J. (2010). Job accessibility and the modal mismatch in Detroit. Journal of Transport Geography, $18,42-54$

Guerra, E. (2013). The new suburbs: Evolving travel behavior, the built environment and subway investments in Mexico City (PhD Dissertation). University of California Transportation Center, University of California Berkeley, Berkeley, CA.

Guerra, E. (2014). The built environment and car use in Mexico City: Is the relationship changing over time? Journal of Planning Education and Research, 34(4), 394-408.

Guerra, E. (2015). The geography of car ownership in Mexico City: A joint model of households' residential location and car ownership decisions. Journal of Transport Geography, 43, 171-180.

Guerra, E. (2017). Does where you live affect how much you spend on transit? The link between urban form and household transit expenditures in Mexico City. Journal of Transport and Land Use, 10(1), 855-878.

Guzmán, L. A., Oviedo, D., \& Rivera, C. (2017). Assessing equity in transport accessibility to work and study: The Bogotá region. Journal of Transport Geography, 58, 236-246.

Guzmán, L. A., \& Oviedo, D. (2018). Accessibility, affordability and equity: Assessing 'pro-poor' public transport subsidies in Bogotá. Transport Policy, 68, 37-51.

Guzmán, L. A., Oviedo, D., \& Cardona, R. (2018). Accessibility changes: Analysis of the integrated public transport system of Bogotá. Sustainability, 10(3958), 1-15.

Hernandez, D. (2018). Uneven mobilities, uneven opportunities: Social distribution of public transport accessibility to jobs and education in Montevideo. Journal of Transport Geography, 67, 119-125.

INEGI. (2010). Censo general de población y vivienda. Augascalientes, Mexico: Instituto Nacional de Geografía Estadística e Informática.

INEGI. (2017). Encuesta origen-destino en hogares de la zona metropolitana del Valle de México. Augascalientes, Mexico: Instituto Nacional de Estadística, Geografía e Informática.

Instituto de Políticas para el Transporte y el Desarrollo, ITDP México. (2014). Transporte público masivo en la zona metropolitana del Valle de México Proyecciones de demanda y soluciones al 2024. México City: Instituto de Políticas para el Transporte y el Desarrollo.

Jaramillo, C., Lizárraga, C., \& Grindlay, A. L. (2012). Spatial disparity in transport social needs and public transport provision in Santiago de Cali (Colombia). Journal of Transport Geography, 24, 340 357.

Kain, J. F. (1968). Housing segregation, negro employment and metropolitan decentralization. Quarterly Journal of Economics, 82, 175-97.

Kawabata, M., \& Shen, Q. (2006). Job accessibility as an indicator of auto-oriented urban structure: A comparison of Boston and Los Angeles with Tokyo. Environment and Planning B, 33(1), 115-130.

Kawabata, M., \& Shen, Q. (2007). Commuting inequality between cars and public transit: The case of the San Francisco Bay Area, 1990-2000. Urban Studies, 44(9), 1759-1780. 
Khattak, A. J., Amerlynck, V. J., \& Quercia, R. G. (2000). Are travel times and distances to work greater for residents of poor urban neighborhoods? Transportation Research Record, 1718, 73-82.

Lee, B. (2007). "Edge" or "edgeless" cities? Urban spatial structure in U.S. metropolitan areas, 1980 to 2000. Journal of Regional Science, 47(3), 479-515.

Lukas, M., \& López-Morales, E. (2018). Real estate production, geographies of mobility and spatial contestation: A two-case study in Santiago de Chile. Journal of Transport Geography, 67, 92-111.

Montejano, J., Caudillo, C., \& Silván, J. (2016). Contesting Mexico City’s alleged polycentric condition through a centrality-mixed land-use composite index. Urban Studies, 53(11), 2380-2396.

Moreno-Monroya, A. I., Lovelaceb, R., \& Ramos, F. R. (2018). Public transport and school location impacts on educational inequalities: Insights from São Paulo. Journal of Transport Geography, 67, $110-118$.

ONU HABITAT. (2008). State of the world's cities 2010/2011. In Bridging the urban divide. London: Earthscan.

Pucci, P., Vecchio, G., Bocchimuzzi, L., \& Lanza, G. (2019). Inequalities in job-related accessibility: Testing an evaluative approach and its policy relevance in Buenos Aires. Applied Geography, 107, $1-11$.

Rossetti, M. A., \& Eversole, B. S. (1993). Journey to work trends in the United States and its major metropolitan areas, 1960-1990. Washington, DC: Federal Highway Administration.

Shen, Q. (1998). Location characteristics of inner-city neighborhoods and employment accessibility of low-wage workers. Environment and Planning B: Planning and Design, 25, 345-365.

Shen, Q. (2000). Spatial and social dimensions of commuting. Journal of the American Planning Association, 66(1), 68-82. doi.10.1080/01944360008976085

Suárez, M., \& Delgado, J. (2009). Is Mexico City polycentric? A trip attraction capacity approach. Urban Studies, 46(10), 2187-2211.

Suárez, M., Murata, M., \& Delgado, J. (2016). Why do the poor travel less? Urban structure, commuting and economic informality in Mexico City. Urban Studies, 53(12), 2548-2566.

Vasconcellos, A. E. (2018). Urban transport policies in Brazil: The creation of a discriminatory mobility system. Journal of Transport Geography, 67, 85-91. 